\title{
Design and Development of Unmanned Hovercraft
}

\author{
Surendar Ganesan \\ Centre for Autonomous System Research \\ Vel Tech Rangarajan Dr. Sagunthala R \& D Institute of Science and Technology, Chennai, India \\ E-mails: suren.ganesh.2007@gmail.com \\ Balasubramanian Esakki \\ Centre for Autonomous System Research \\ Vel Tech Rangarajan Dr. Sagunthala R \& D Institute of Science and Technology, Chennai, India \\ Corresponding author: esak.bala@gmail.com
}

(Received April 11, 2019; Accepted July 4, 2019)

\begin{abstract}
The present study focuses on the development and performance analysis of unmanned hovercraft. The inherent characteristics of hovercraft such as hovering and gliding on diverse surfaces like water and land are intended for pollution control in remote water bodies. The vehicle is designed with bag skirt configuration for ease and smooth functioning on multiple terrains. Computer Aided Design (CAD) model with incorporation of spraying mechanism as a payload is conceptualized. Computational Fluid Dynamic (CFD) analysis at internal flow condition is performed and bag pressure of the skirt is assessed. The prototype model of vehicle to accommodate a payload of $0.8 \mathrm{~kg}$ is fabricated from suitable lightweight materials and the experiments are conducted to explore the desired operation of hovering and forward thrust systems. The performance studies are made with velocity component in linear direction on land and water surfaces.
\end{abstract}

Keywords- Unmanned hovercraft, Bag skirt, Air cushion vehicle, CFD, Spraying system.

\section{Introduction}

The design and development of amphibious vehicle are becoming a trend around the world due to its various applications like surveillance, patrolling, monitoring, payload delivery, photography, data collections and many hazardous jobs (Yan et al., 2010). These vehicles are well known for its speed characteristic by which it could travel in water and land in high speed. The reason behind this characteristic is the hovercraft technology (Esakki et al., 2018). The development of amphibious vehicle incorporated with spraying mechanism can be used for water body restoration in order to eradicate the effects of Eutrophication, weeds and mosquito control (Pope, 1976). It plays a major role in navigating both aquatic and terrestrial purposes.

Hovercraft uses aerostatic principle through which it can travel effectively over the water surface by reducing the water drag. Hovercraft can be classified into Air Cushion Vehicle (ACV) and Surface Effect Ship (SES) (Yun and Bliault, 2000), out of which ACV is highly recommended due to its shallow draft and amphibious characteristics. In a series of high-speed watercraft, ACV's are excellent in terms of less wave drag and speed. The bag and finger skirts are recognized as the most efficient skirt types for modern ACV's (Chung and Jung, 2004) due to its superior air cushion characteristics. Though it travels over the water surface, (without making contact with water), it doesn't create any harm to aquatic beings. It makes less pressure on the earth surface as compared to the pressure created by human footprints (hovercraft.org, 2013). Due to this significant behaviour, hovercraft are considered as an ideal platform for environmental monitoring in coastal regions (Lamberson and Nelson, 2002). Also, the water level may vary with time at places where 
International Journal of Mathematical, Engineering and Management Sciences

Vol. 4, No. 5, 1180-1195, 2019

https://dx.doi.org/10.33889/IJMEMS.2019.4.5-093

water samples have to be collected, which could cause many issues. So, it creates the need for an amphibious vehicle to travel on both water and land surfaces. In recent years many researchers have involved themselves in the development of design and control of the amphibious vehicle (García, 2014).

The much needed and most challenging thing is making an amphibian with desired characteristics. The design is dominant by multi physics phenomenon of aerodynamics and hydrodynamics (Hasnan and Wahab, 2010) which brings the need for more evaluation and precise calculations of design. Frictionless movement and fast transportation are admired nature about the hovercraft. Few researchers focused on design and development of hovercraft. Amiruddin et al. (2011) constructed a hovercraft with an aluminium base for a single person to travel. Schleigh (2006) fabricated a hovercraft model and controlled its operation to track a line. Gera et al. (2009) designed and fabricated an industry application hovercraft which runs on pressure lines from industries. Hein and Liaw (2013) developed a one-seater hovercraft, consequently he investigated hovering and propulsion system of the vehicle (Anguah and Szapiro, 2009). The literature studies of hovercraft design are not addressed the design challenges of unmanned amphibious vehicles. Most of the small size hovercraft designs (Okafor, 2013; Noor et al., 2016; Saad et al., 2018) are made for hobby purpose only which is not up to the level of performing experiments in water bodies. This paved the way to develop a highly reliable small size hovercraft platform for conducting various experiments in water and land for environmental monitoring. In this paper, the authors focus on major design drivers of hovercraft and validate the design through simulating the conditions using Computational Fluid Dynamic (CFD) platform and also the performance of the vehicle is tested.

\section{Hovercraft Design}

The structure of a hovercraft is comprised of the hull, duct, plenum chamber, and skirt as shown in Figure 1. The hull is the rigid structure on hovercraft to accommodate most of the components. The duct is the air passage for the intake of air into the system. The plenum chamber lies between the top and bottom of the hovercraft and it also helps for the air to diversify into all regions around the skirt equally. The skirt in hovercraft acts as a wall to cover the air cushion underneath the vehicle.

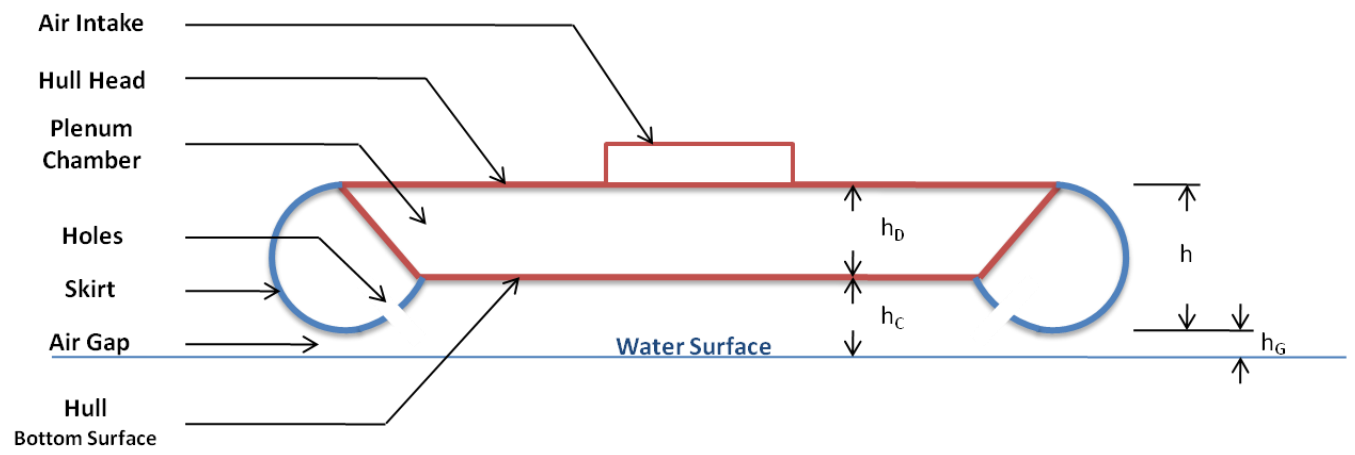

Figure 1. Schematic diagram of hovercraft

The skirt design determines the life of an ACV's to hover. The design of the skirt mainly considers the type of flow and the number of air exit holes. Even a slight tear could deflate the bag and leads 
to serious damages. An improper design will reduce the operations and increase the chances of wear and tear. Different types of skirts are in use (Amyot, 2013) that ranges from simple to complex to manufacture and repair. According to operational requirements, skirts have to be selected. The present case is to provide equivalent flow around the skirt and also to make more reliable and stable structure. Hence, bag skirt with plenum chamber design is selected.

The design cycle shown in Figure 2, involves with the setting of requirements and conditions such as length to width ratio and pressure ratio with the knowledge of hovercraft design based on the mission which is used to determine the specific characteristics of a vehicle. Higher the pressure ratio will make the skirt hard and it is suitable for high-speed operations in smooth water. The major design parameters like cushion pressure, cushion Area, air escaping the area, air escaping velocity are estimated using the standard relationships (Amyot, 2013) and corresponding CFD analysis is performed to validate the aspect of plenum design. The prototype is fabricated to test the hover characteristics of the vehicle at different conditions which help to finalize the design.

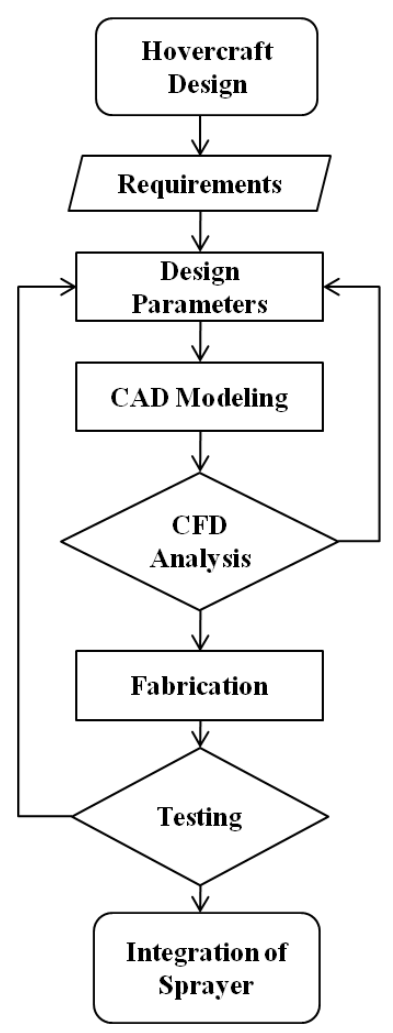

Figure 2. Hovercraft design chart

\subsection{Design Requirements}

The amphibious vehicle is going to be intended for algaecide missions in water bodies with a spraying mechanism as a payload. The designed hovercraft needs to support the primary loads of structure and sub systems for which a room for on-board components needs to be provided. The 
International Journal of Mathematical, Engineering and Management Sciences

Vol. 4, No. 5, 1180-1195, 2019

https://dx.doi.org/10.33889/IJMEMS.2019.4.5-093

on-board components are listed in Table 2. The total estimated weight of the system is $2 \mathrm{~kg}$ and payload is about $0.8 \mathrm{~kg}$. The payload fraction is set into $40 \%$. For mission like spraying, the vehicle needs to carry the sprayer and storage of the respective fluid and glides on the water surface for an endurance of 20 mins within a range of $1 \mathrm{~km}$ at an operating speed of $5 \mathrm{kmph}$. In order to satisfy these constraints, the following design process is considered.

\subsection{Design Parameters}

The design of hovercraft involves with an estimation of critical parameters and sizing of major hovercraft components. The higher surface area for effective cushion pressure leads to determine the length $(l)$ of the vehicle. The longitudinal and transverse stabilities of hovercraft will be affected when the length to width ratio is greater than half and lesser than half respectively. For better stability purpose, the width $(w)$ of the vehicle is set as half of its length. The plenum chamber lies between the top and bottom surfaces of hull whose height is called as hull depth $\left(h_{D}\right)$. The condition of water in the operating environment and the obstacles present in water such as rocks, waves and surfs are to be considered while determining cushion clearance $\left(h_{C}\right)$. The gap which allows the excess of air to escape from the cushion region to produce lift is the hover gap $\left(h_{G}\right)$ and it helps the vehicle to be in hover condition. The hover gap is controlled by the pressure built inside the cushion region. The height of the hovercraft $(h)$ is measured from the bottom of the skirt to top surface of the hull. The effective region at the bottom of the hull is considered as cushion area $\left(A_{C}\right)$ which differs from the top surface area of the vehicle. The amount of weight lifted by a hovercraft determines the cushion pressure $\left(P_{C}\right)$ to be produced which is directly proportional to the total weight of the vehicle. The stagnation of flow inside the plenum chamber and skirt will produce the bag pressure $\left(P_{B}\right)$ which is higher in value than cushion pressure. Based up on the design parameters we arrived at the design summary of our hovercraft which is given in Table 1 .

Table 1. Design summary of hovercraft

\begin{tabular}{|c|c|c|c|}
\hline Design Parameters & Empirical Relation & \multicolumn{2}{|c|}{ Value } \\
\hline length $(l)$ & - & 0.6 & $\mathrm{~m}$ \\
\hline width $(w)$ & $w=l \times 0.5$ & 0.3 & $\mathrm{~m}$ \\
\hline hull depth $\left(h_{D}\right)$ & $h_{D}=l \times 0.1$ & 0.06 & $\mathrm{~m}$ \\
\hline cushion clearance $\left(\boldsymbol{h}_{C}\right)$ & $h_{C}=l \times 0.07$ & 0.042 & $\mathrm{~m}$ \\
\hline hover gap $\left(\boldsymbol{h}_{G}\right)$ & - & 0.002 & $\mathrm{~m}$ \\
\hline hovercraft height $(h)$ & $h=h_{D}+h_{C}-h_{G}$ & 0.102 & $\mathrm{~m}$ \\
\hline cushion area $\left(A_{C}\right)$ & $A_{C}=l_{b} \times w_{b}$ & 0.0836 & $\mathrm{~m}^{2}$ \\
\hline cushion pressure $\left(\boldsymbol{P}_{C}\right)$ & $P_{C}=W / A_{C}$ & 146.68 & $\mathrm{~N} / \mathrm{m}^{2}$ \\
\hline air escaping velocity $\left(V_{e}\right)$ & $V_{e}=\sqrt{2 P_{C} / \rho}$ & 15.47 & $\mathrm{~m} / \mathrm{s}$ \\
\hline air escaping area $\left(A_{e}\right)$ & $A_{e}=(2 l \times 2 w) h_{G}$ & 0.0036 & $\mathrm{~m}^{2}$ \\
\hline escaping air flow rate $\left(Q_{e}\right)$ & $Q_{e}=A_{e} \times V_{e}$ & 0.0557 & $\mathrm{~m}^{3} / \mathrm{s}$ \\
\hline power required $\left(P_{r}\right)$ & $P_{r}=\frac{Q_{e} \times \rho \times V_{e}^{2}}{2}$ & 80.13 & $\mathrm{~N} \cdot \mathrm{m} / \mathrm{s}$ \\
\hline bag pressure $\left(P_{B}\right)$ & $P_{B}=P_{C} \times 1.2$ & 176.01 & $\mathrm{~N} / \mathrm{m}^{2}$ \\
\hline no. of air exit holes $(N)$ & - & 44 & - \\
\hline air exit hole area $\left(A_{h}\right)$ & $A_{h}=\frac{Q_{e} / N}{\left(C \times(2 / \rho) \times\left(P_{B}-P_{c}\right)^{1 / 2}\right)}$ & 0.0002 & $\mathrm{~m}^{2}$ \\
\hline
\end{tabular}


International Journal of Mathematical, Engineering and Management Sciences

Vol. 4, No. 5, 1180-1195, 2019

https://dx.doi.org/10.33889/IJMEMS.2019.4.5-093

Table 2. List of on-board components

\begin{tabular}{|c|c|c|}
\hline Component Name & Specification & Count \\
\hline Electric Ducted Fan & KV 3900, 70 mm Diameter & 1 \\
\hline BLDC Motor & KV 920 & 1 \\
\hline Propeller & 5 Inch, 3 blades & 1 \\
\hline Batteries & $3 \mathrm{~S}, 4000 \mathrm{mAH}$ & 2 \\
\hline Voltage Regulator & Input: 7.4 to 22.2 Volt \\
\hline Electronic Speed Control & Output: 5 Volt, 3 Amps & 1 \\
\hline Transmitter \& Receiver & $40 \mathrm{Amps}$ & 1 \\
\hline Servo & $2.4 \mathrm{GHz}, 6 \mathrm{Channel}$ & 1 \\
\hline
\end{tabular}

\subsection{Performance Parameters}

The performance of hovercraft is related with the forces acting on it, which is shown in Figure 3. The major forces that can affect the forward motion of the vehicle are drag and resistance force. The drag component of the vehicle is changing with operating conditions and resistance force is varied with the surface of operation.

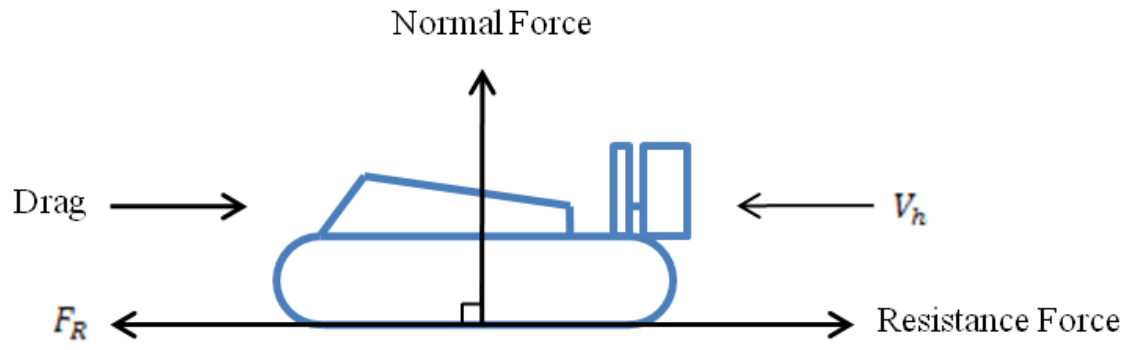

Figure 3. Forces acting on the hovercraft

The amount of thrust force required to overcome all other forces to make the hovercraft in stable condition is given by (Schaltz and Soylu, 2011).

$$
F_{R}=M_{h} \cdot g \cdot C_{R}+1 / 2 \rho\left(V_{h}+V_{a}\right)^{2} A_{F} C_{d}
$$

\begin{tabular}{|c|c|c|c|}
\hline where, & $F_{R}$ & {$[\mathrm{~N}]$} & Thrust required in the forward direction \\
\hline & $M_{h}$ & {$[\mathrm{~kg}]$} & Mass of the hovercraft \\
\hline & $\mathrm{g}$ & {$\left[\mathrm{m} / \mathrm{s}^{2}\right]$} & Acceleration due to gravity \\
\hline & $C_{R}$ & - & Coefficient of resistance in surface \\
\hline & $\rho$ & {$\left[\mathrm{kg} / \mathrm{m}^{3}\right]$} & Density of air \\
\hline & $V_{h}$ & {$[m / s]$} & Velocity of the hovercraft \\
\hline & $V_{a}$ & {$[m / s]$} & Head wind velocity \\
\hline & $A_{F}$ & {$\left[m^{2}\right]$} & Frontal area of hovercraft \\
\hline & $C_{d}$ & - & Coefficient of drag \\
\hline
\end{tabular}


International Journal of Mathematical, Engineering and Management Sciences

Vol. 4, No. 5, 1180-1195, 2019

https://dx.doi.org/10.33889/IJMEMS.2019.4.5-093

It is evident that, the thrust required is governed by the normal force, gravity and drag of the vehicle. Drag will oppose the forward motion of the vehicle which will increase the power consumption of the thrusting system to maintain the same function. The amount of drag exerted on a vehicle for different speed shown in Figure 4 is used to set the operating limits for a vehicle.

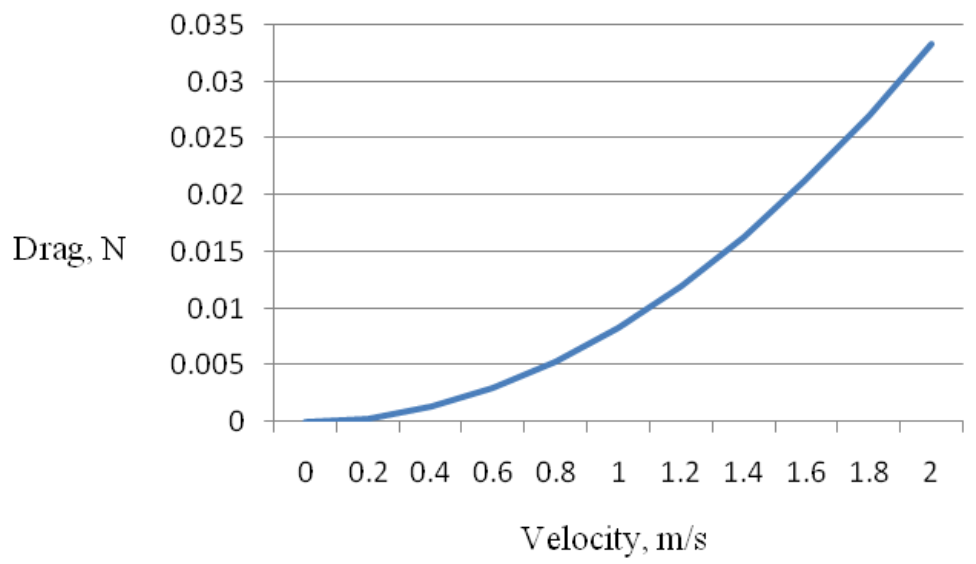

Figure 4. Drag of hovercraft

\section{CFD Analysis of Hovercraft}

The CFD analysis is used to reveal the flow characteristics inside the plenum chamber of hovercraft whose cross-sectional area for airflow passage is $70 \mathrm{x} 75 \mathrm{~mm}$. Understanding the interaction of airflow with chamber walls and behaviour of flow in this regime is of paramount of interest in designing plenum chamber. The internal pressure due to the inflation of the skirt is analyzed by using the CFD platform (Pavăl et al., 2018). From this analysis, the bag pressure and exit velocity at the holes provided in the bottom of the skirt are obtained which helps to avoid the wear and tear damages of the material. The continuous flow of air intake and uniformity of air exit through the holes will regulate and keep the desired pressure inside the bag. There are chances for leakage in joints of the skirt if the pressure is not uniform and further it leads to damages. The turbulence phenomenon, stagnation points, and recirculation of air inside the chamber can be seen from CFD analysis which could help in avoiding the back pressure and chamber choking of the system.

\subsection{Modelling}

The CAD model shown in Figure 5 is considered to perform CFD analysis for examining the flow characteristics around the vehicle. The hovercraft body is taken as a computational domain to simulate the flow inside the chamber and edges of the domain are set as boundary limits for the CFD analysis. The ducted fan of hovercraft rotates at a maximum speed of $2000 \mathrm{rpm}$ to generate a velocity of $12.5 \mathrm{~m} / \mathrm{sec}$, which is used to exert the pressure at the internal periphery of the skirt is given as the boundary condition to simulate the internal flow of the skirt. 
International Journal of Mathematical, Engineering and Management Sciences

Vol. 4, No. 5, 1180-1195, 2019

https://dx.doi.org/10.33889/IJMEMS.2019.4.5-093

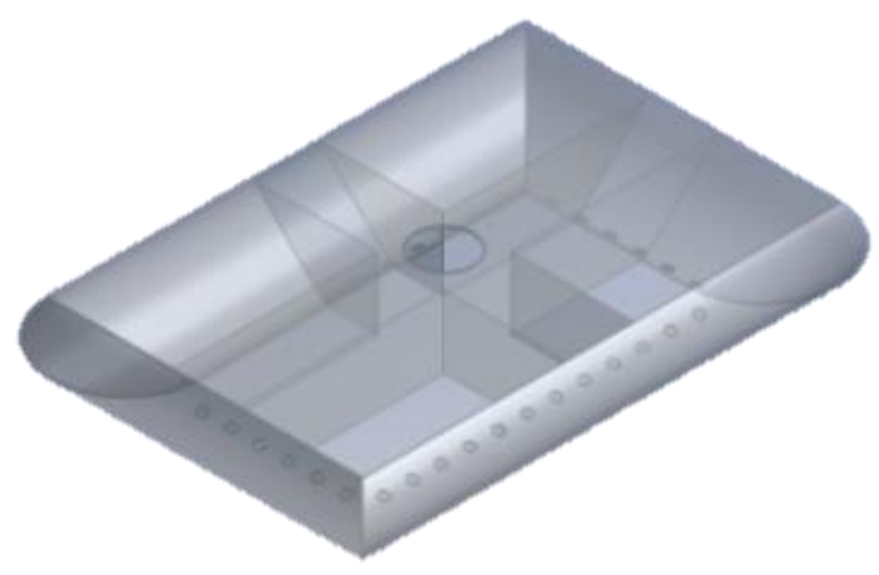

Figure 5. Isometric view of skirt domain

The generation of the grid is achieved in ICEM tool and tetrahedral mesh is used for this internal flow analyses with the total number of 109792 elements. The quality of the mesh is validated through performing orthogonality and skewness checks which are well within the limit.

\subsection{Simulation of Internal Flow Analysis}

The CFD analysis is performed in ANSYS Fluent post processor and the results predicted that there is a pressure rise inside the skirt region which is similar with our calculated bag pressure, shown in Figure 6.

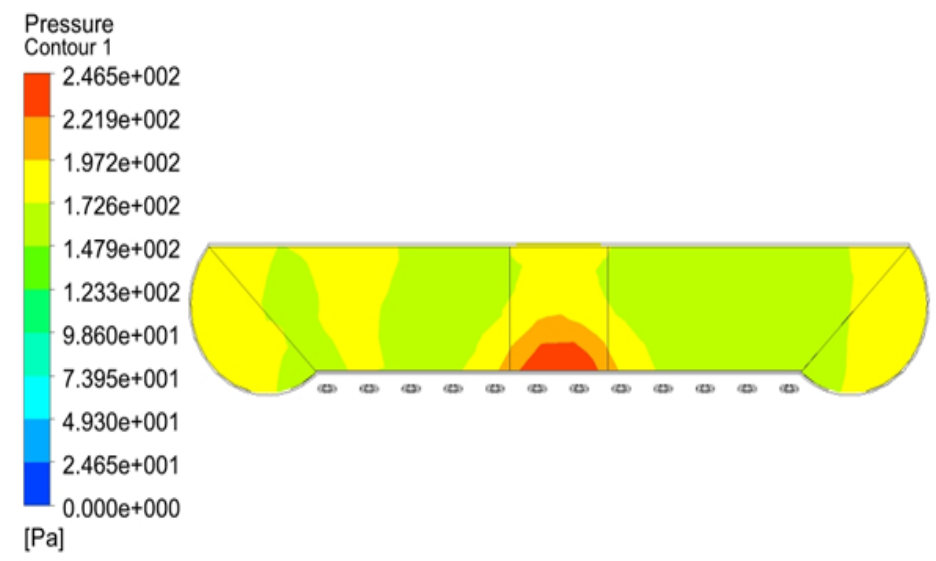

Figure 6. Pressure contour at YZ plane of hovercraft 
International Journal of Mathematical, Engineering and Management Sciences

Vol. 4, No. 5, 1180-1195, 2019

https://dx.doi.org/10.33889/IJMEMS.2019.4.5-093

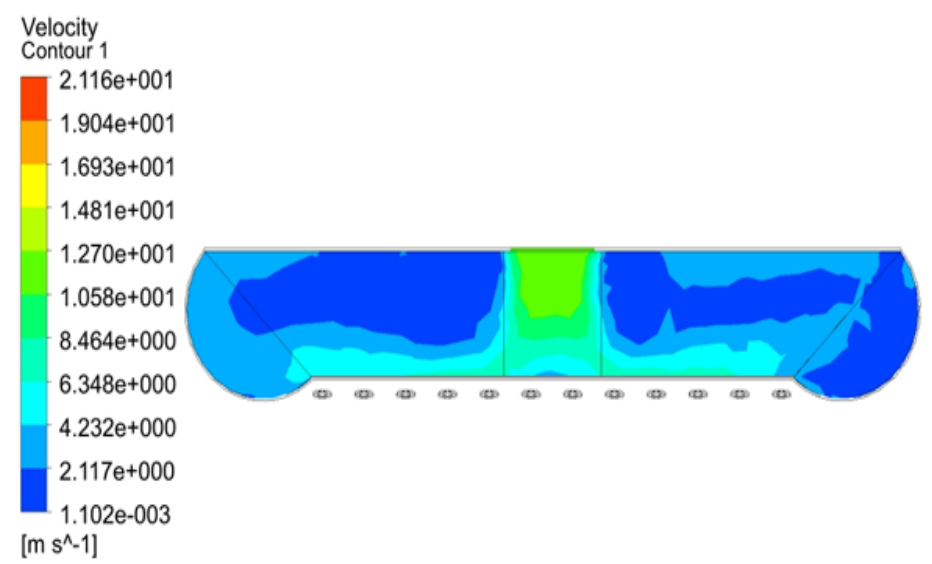

Figure 7. Velocity contour at YZ plane of hovercraft

The high velocity of air starts entering from the intake region and the flows get normalized in the plenum chamber and making the skirt nodular. The velocity profile shown in Figure 7 depicts the drop-in velocity from $12.5 \mathrm{~m} / \mathrm{sec}$ to $0.001 \mathrm{~m} / \mathrm{sec}$ due to stagnation of flow (kinetic energy loss) inside the plenum chamber. This stagnation of flow makes recirculation of air at the boundary of the skirt and finally, it exits through the holes at a velocity of $4 \mathrm{~m} / \mathrm{sec}$. It is observed that flow characteristics inside the skirt are uniform without any blockages to ensure the stability of the vehicle. The improper flow circulation and blockages inside the bag will result in uneven bulging of skirt which could change the air escaping area $A_{e}$. The variations in air gap results in-stability and it makes the vehicle to consume more power to maintain the cushion pressure.

\section{Fabrication of Hovercraft Prototype}

The major fabrication works of the prototype model are divided into tailoring of skirt and making of the hull. The tailoring of the skirt is quite complex which involves material selection, template making and stitching. The property of water resistant, non-homogeneity and tensile strength are to be considered while selecting the skirt material. Ripstop Nylon shown in Figure 8 which possess high tensile strength of $660 \mathrm{~N} / 5 \mathrm{~cm} \times 480 \mathrm{~N} / 5 \mathrm{~cm}$ (non-homogenous material) and tearing strength of $30 \mathrm{~N} / 5 \mathrm{~cm}$ (Force/Area $\mathrm{x}$ Thickness) is considered as skirt material for the various operating conditions of hovercraft which helps to avoid tearing during the time of failure. Nylon impregnated with urethane can be an alternate skirt material to withstand the external loads and resistance to environmental conditions. The preparation of the skirt template is carried out using the 'Parallel Line Method' technique and the skirt panels are incised which are shown in Figure 9.

The skirt is stitched accordingly to distribute and maintain the equal amount of flow on all the sides. Standard aluminium frames are used for withstanding the load produced by the skirt on the hull. The plenum is made up of high-density foam to provide internal support for the top and bottom surface of the hull. The suitable adhesives which are insoluble in water are used in plenum chamber to stick with hull surfaces. Water may get inside the plenum chamber through air exit holes when EDF is in off condition. It can be flushed by switching on the EDF. In this case, buoyant chambers will keep the vehicle away from drowning. The hole of $\varnothing 0.07 \mathrm{~m}$ was cut at the middle of the hull to erect duct fan. Then, the stitched skirt is attached to the hull surface as shown in Figure 11 for achieving efficient cushioning phenomenon. The total number of holes is assumed to be 44 
International Journal of Mathematical, Engineering and Management Sciences

Vol. 4, No. 5, 1180-1195, 2019

https://dx.doi.org/10.33889/IJMEMS.2019.4.5-093

of $\varnothing 0.015 \mathrm{~m}$ each that are punched under the inner walls of the skirt as shown in Figure 10. Based on the number of holes, the area of exit hole varies.

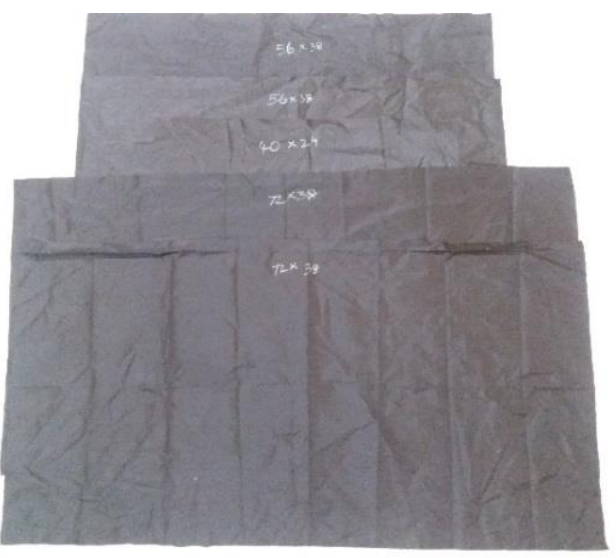

Figure 8. Material used for fabrication of skirt

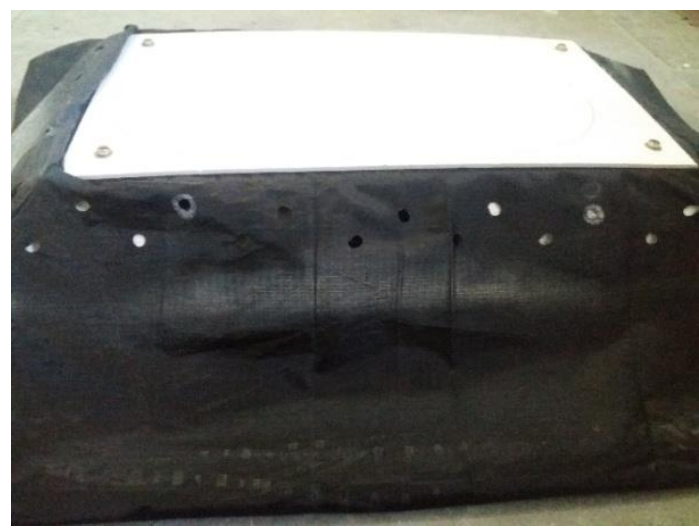

Figure 10. Holes punched underneath of skirt

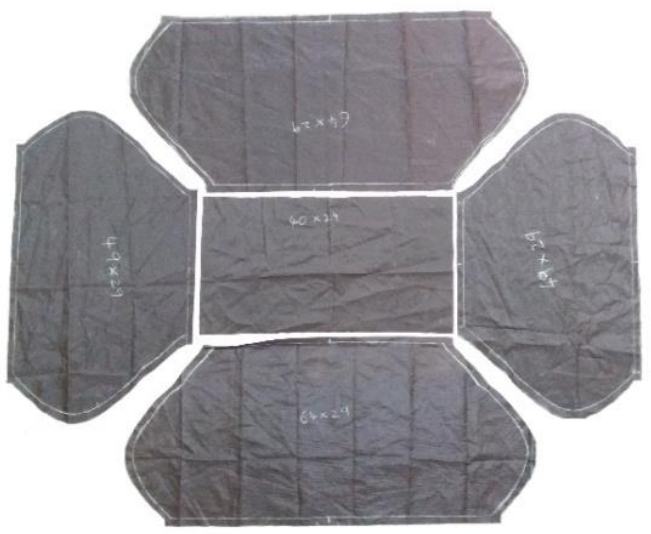

Figure 9. Skirt panels before sewing

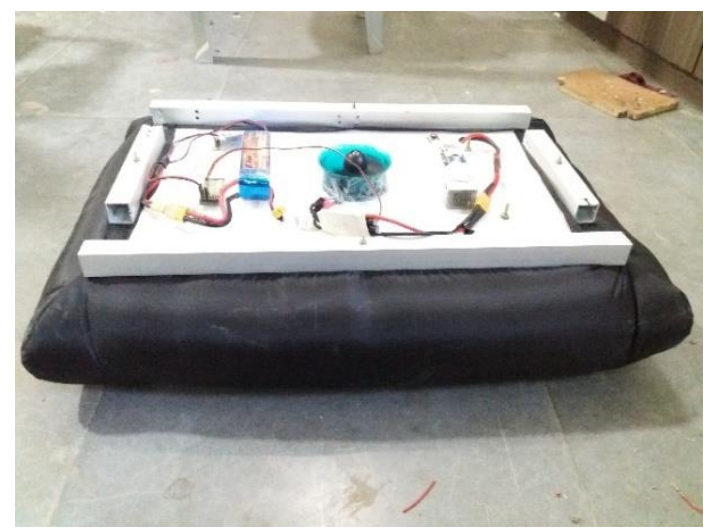

Figure 11. Skirt attached with hull

\section{Testing of Hovercraft}

The prototype model is developed to test the hypothesis of design characteristics in static and dynamic conditions. The static tests are carried out to assess the generation of lift and thrust at the nominal condition of cushion pressure. The velocity performance of the vehicle is experimented through conducting dynamic tests.

\section{Case - (i): Testing of Lifting System}

In this static test, the battery powered EDF is used to inflate the skirt and the vehicle is subject to hover at the professed condition of $2 \mathrm{~mm}$ air gap on a plain floor for a respective air intake velocity which is shown in Figure 13. In this pressure test, one end of the U-Tube manometer is opened to the atmosphere and another end is connected with the vehicle as shown in Figure 12 to find the 
International Journal of Mathematical, Engineering and Management Sciences

Vol. 4, No. 5, 1180-1195, 2019

https://dx.doi.org/10.33889/IJMEMS.2019.4.5-093

amount of pressure build inside the cushion and bag regions. The measured pressure head readings from the manometer are given in Table 3 helps to determine the loss characteristics of the air duct and also to confirm the ratio of cushion to bag pressure as 1.2. The static cushion stability of the skirt in the longitudinal and transverse direction is verified in hovering condition to substantiate it.

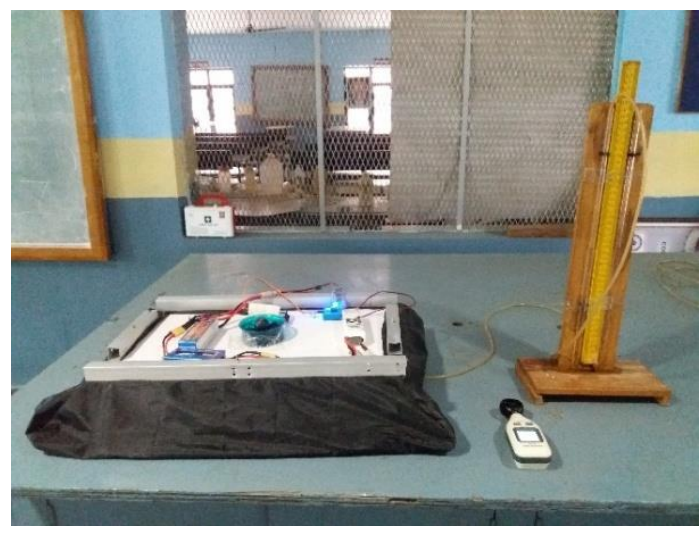

Figure 12. Manometer is connected with hovercraft

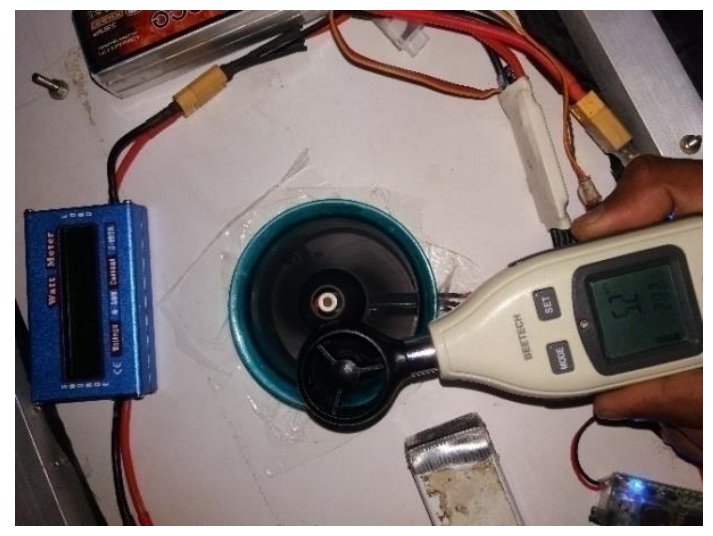

Figure 13. Measurement of air intake velocity

Table 3. Manometer reading of skirt test

\begin{tabular}{|c|c|c|c|c|}
\hline Location & $\mathbf{h}_{\mathbf{0}}(\mathbf{c m})$ & $\mathbf{h}_{\mathbf{1}}(\mathbf{c m})$ & $\mathbf{h}_{\mathbf{p}}=\mathbf{h}_{\mathbf{1}}-\mathbf{h}_{\mathbf{0}}(\mathbf{c m})$ & $\begin{array}{c}\text { Pressure } \\
\left(\mathbf{N} / \mathbf{m}^{\mathbf{2}}\right)\end{array}$ \\
\hline Cushion & 23.7 & 25.1 & 1.4 & 140.81 \\
\hline Bag & 23.8 & 25.5 & 1.7 & 168.97 \\
\hline
\end{tabular}

\section{Case - (ii): Testing of Forward Thrust System}

The rotation of propeller provides the required thrust for the forward motion of Hovercraft. The forward thrust system shown in Figure 14 is tested in a test rig for various throttling conditions and maximum thrust is measured which is given in Table 4. The outcome of this test helps in predicting the excess thrust available and maximum operating condition of a system (Miková et al., 2014). The amount of current drawn is used for sizing the battery and to control the forward motion of the vehicle through controlling the thrust motor. The maximum power consumption of the system including payload is estimated as $125 \mathrm{~W}$. 
International Journal of Mathematical, Engineering and Management Sciences

Vol. 4, No. 5, 1180-1195, 2019

https://dx.doi.org/10.33889/IJMEMS.2019.4.5-093

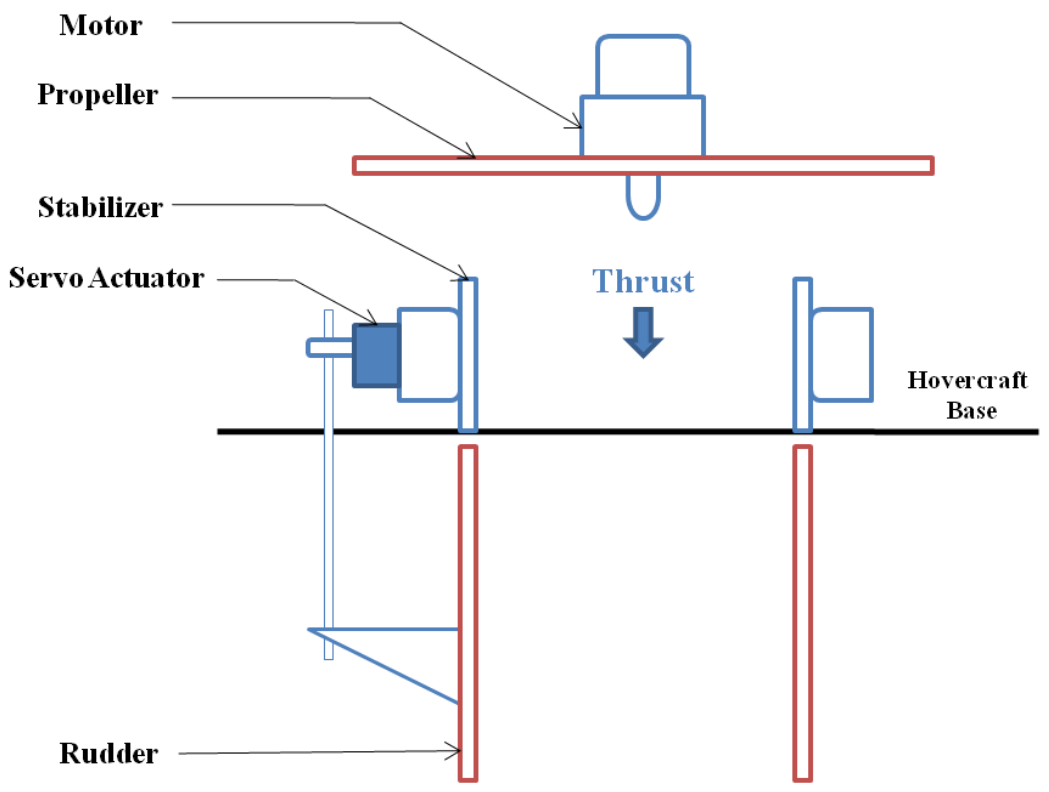

Figure 14. Forward thrust and actuation system

Table 4. Tabulation of forward thrust for different throttle positions

\begin{tabular}{|c|c|c|c|c|}
\hline Throttle Position & $\begin{array}{c}\text { Power } \\
\text { (watts) }\end{array}$ & $\begin{array}{c}\text { Voltage } \\
\text { (V) }\end{array}$ & $\begin{array}{c}\text { Current } \\
(\mathbf{A})\end{array}$ & $\begin{array}{c}\text { Thrust } \\
\text { (N) }\end{array}$ \\
\hline $\mathbf{1}$ & 05.9 & 12.60 & 0.48 & 0.29 \\
\hline $\mathbf{2}$ & 12.3 & 12.44 & 1.00 & 0.75 \\
\hline $\mathbf{3}$ & 17.2 & 12.41 & 1.40 & 1.07 \\
\hline $\mathbf{4}$ & 21.4 & 12.37 & 1.73 & 1.37 \\
\hline $\mathbf{5}$ & 28.0 & 12.31 & 2.30 & 1.72 \\
\hline $\mathbf{6}$ & 34.5 & 12.25 & 2.50 & 2.09 \\
\hline
\end{tabular}

Case - (iii): Dynamic Testing

The velocity performance test of hovercraft is carried out in a linear direction between the fixed checkpoints of A and B (5m) on land and water surfaces as shown in Figure 15.

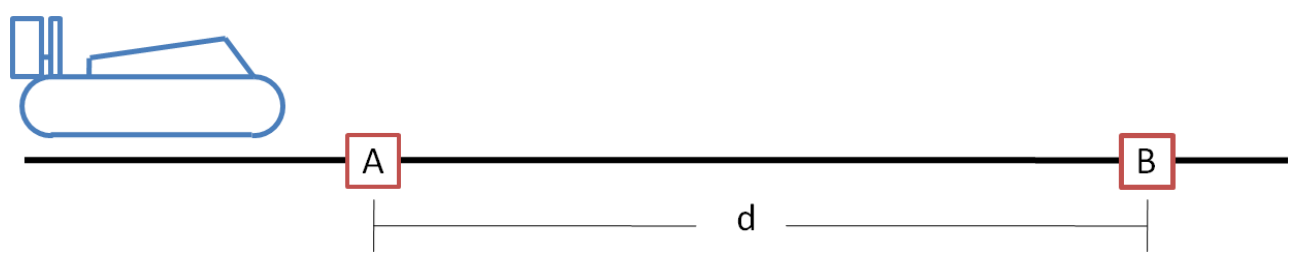

Figure 15. Performance testing of hovercraft 
International Journal of Mathematical, Engineering and Management Sciences

Vol. 4, No. 5, 1180-1195, 2019

https://dx.doi.org/10.33889/IJMEMS.2019.4.5-093

The hovercraft testing in land surface shown in Figure 16 is conducted in our university under indoor conditions. The testing is conducted on plain floor with the absence of abnormal environmental disturbances. The power requirement for lifting the fan system is set to certain wattage based on Table 1. The air cushion under the skirt is maintained constant for all of the test periods. The forward motion of the hovercraft system is tested for various throttle positions as each position of throttle produces a specific amount of thrust. The time taken by the system to travel from checkpoint A to B for specific thrust is measured and the relative velocity is calculated which is given in Table 5.

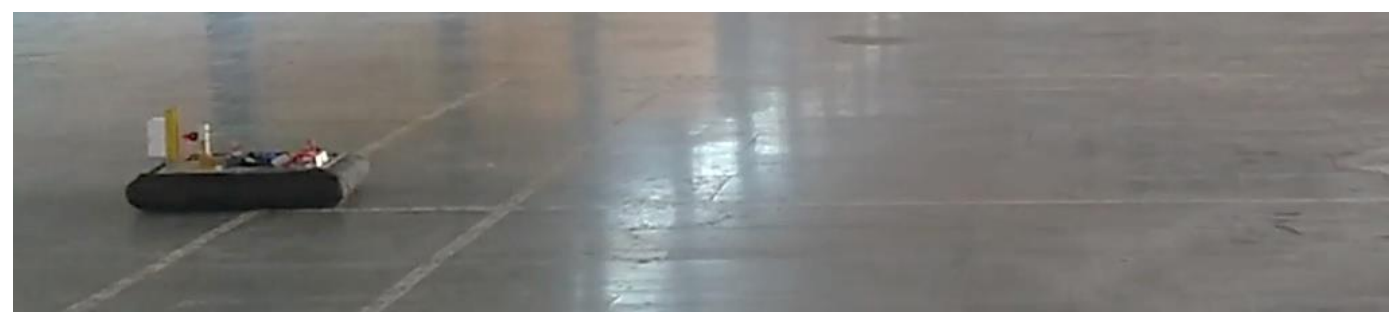

Figure 16. Testing of hovercraft in floor

The performance of the vehicle on the water surface (Figure 17) is tested between a fixed checkpoint in the moderate breeze of $8 \mathrm{~m} / \mathrm{s}$ NE at Kollumedu Lake in the month of Jan'19. The test results are given in Table 6 in which for various relative velocities, the drag component of hovercraft is increasing from $0.585 \mathrm{~N}$ to $0.649 \mathrm{~N}$ due to wind conditions.

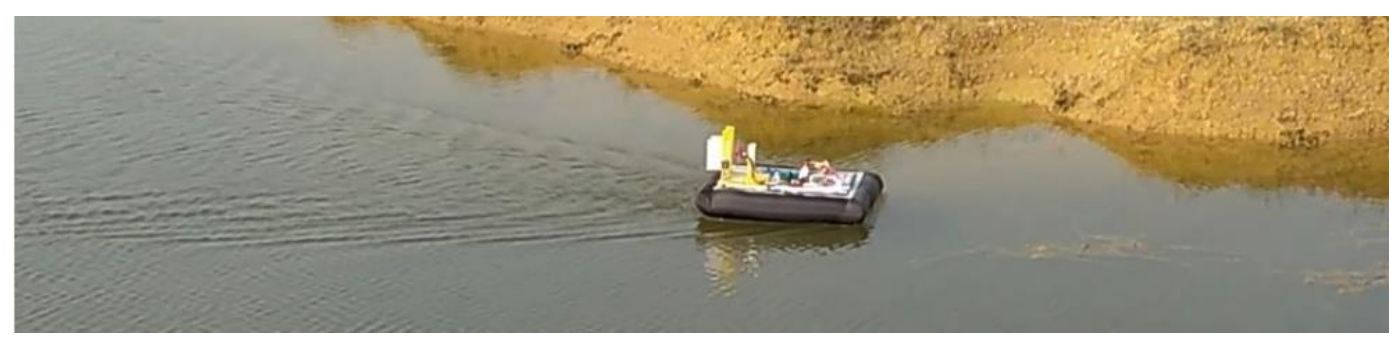

Figure 17. Testing of hovercraft in water

Table 5. Performance of hovercraft in land

\begin{tabular}{|c|c|c|c|c|c|}
\hline \multirow{2}{*}{$\begin{array}{c}\text { Throttle } \\
\text { Position }\end{array}$} & $\begin{array}{c}\text { Time } \\
(\mathbf{s e c})\end{array}$ & $\begin{array}{c}\text { Vehicle Velocity } \\
(\mathbf{m} / \mathbf{s e c})\end{array}$ & $\begin{array}{c}\text { Thrust } \\
(\mathbf{N})\end{array}$ & $\begin{array}{c}\text { Drag } \\
(\mathbf{N})\end{array}$ & $\mathbf{C}_{\mathbf{R}}$ \\
\hline 2.5 & 6 & 0.833 & 0.91 & 0.005 & 0.452 \\
\hline 4 & 4 & 1.250 & 1.37 & 0.013 & 0.678 \\
\hline 5 & 3 & 1.660 & 1.72 & 0.022 & 0.848 \\
\hline
\end{tabular}


International Journal of Mathematical, Engineering and Management Sciences

Vol. 4, No. 5, 1180-1195, 2019

https://dx.doi.org/10.33889/IJMEMS.2019.4.5-093

Table 6. Performance of hovercraft in water

\begin{tabular}{|c|c|c|c|c|c|}
\hline \multirow{2}{*}{$\begin{array}{c}\text { Throttle } \\
\text { Position }\end{array}$} & \multicolumn{5}{|c|}{ Water Surface } \\
\cline { 2 - 6 } & $\begin{array}{c}\text { Time } \\
(\mathbf{s e c})\end{array}$ & $\begin{array}{c}\text { Vehicle Velocity } \\
(\mathbf{m} / \mathbf{s e c})\end{array}$ & $\begin{array}{c}\text { Thrust } \\
(\mathbf{N})\end{array}$ & $\begin{array}{c}\text { Drag } \\
(\mathbf{N})\end{array}$ & $\mathbf{C}_{\mathbf{R}}$ \\
\hline 2.5 & 13 & 0.384 & 0.91 & 0.585 & 0.162 \\
\hline 4 & 9 & 0.555 & 1.37 & 0.609 & 0.380 \\
\hline 5 & 6 & 0.833 & 1.72 & 0.649 & 0.535 \\
\hline
\end{tabular}

Resistance coefficient is the factor of total surface resistance of an ACV. The influence of coefficient of resistance $\left(C_{R}\right)$ on various surfaces with increase in forward velocity limited to $0.8 \mathrm{~m} / \mathrm{sec}$ is evaluated. Figure 18 is the comparative graph of hovercraft performance in land and water surfaces. Similar kind of comparative graphs is discussed in the work of Anter et al. (2017). A linear relationship is seen when the vehicle moving on land surface and non-linear behaviour is experienced at hovering on the water surface. The resistance force acting on the plain floor is less as compared with water surface because the propagation of waves in water provides more opposing force for forward motion which is evident from the test results. Thus, the vehicle can operate efficiently in waters for lower velocity and in the land surface for higher velocities.

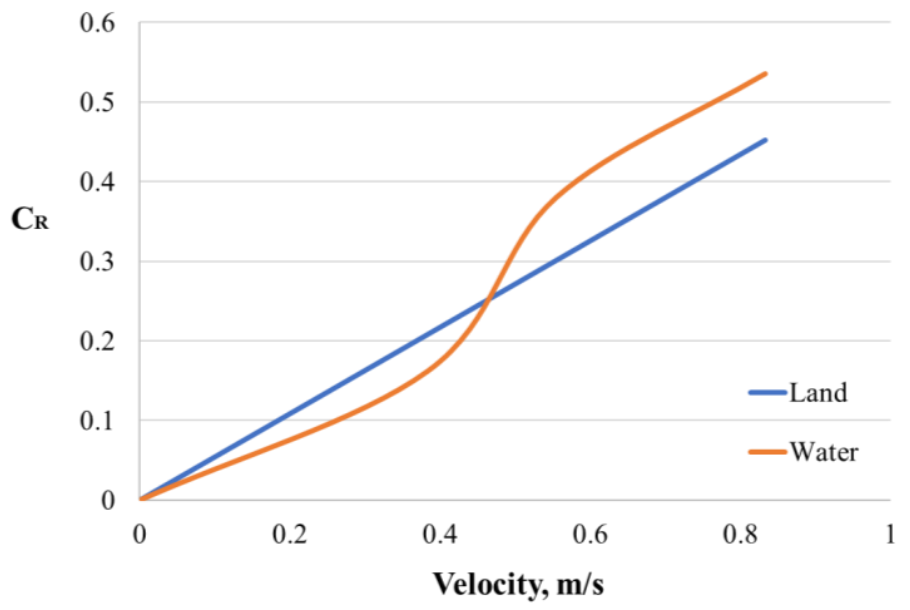

Figure 18. Resistance curve of hovercraft

\section{Integration of Sprayer with Hovercraft}

The spraying of algaecide on water bodies like lakes, ponds and other water storages will help to clear and control the eutrophication (Lynch, 2009). Spraying on remote water body regions is effectively achieved by using unmanned hovercraft system. Based on the type of algae, suitable algaecide is to be selected and used in the system. The spraying system shown in Figure 19 comprises of components such as storage tanks for algaecide, a pump to maintain the flow, pipelines for feed and nozzle for atomizing which is capable to spray $600 \mathrm{ml}$ of algaecide at a discharge rate of 0.1 litre/min per cycle. 
International Journal of Mathematical, Engineering and Management Sciences

Vol. 4, No. 5, 1180-1195, 2019

https://dx.doi.org/10.33889/IJMEMS.2019.4.5-093

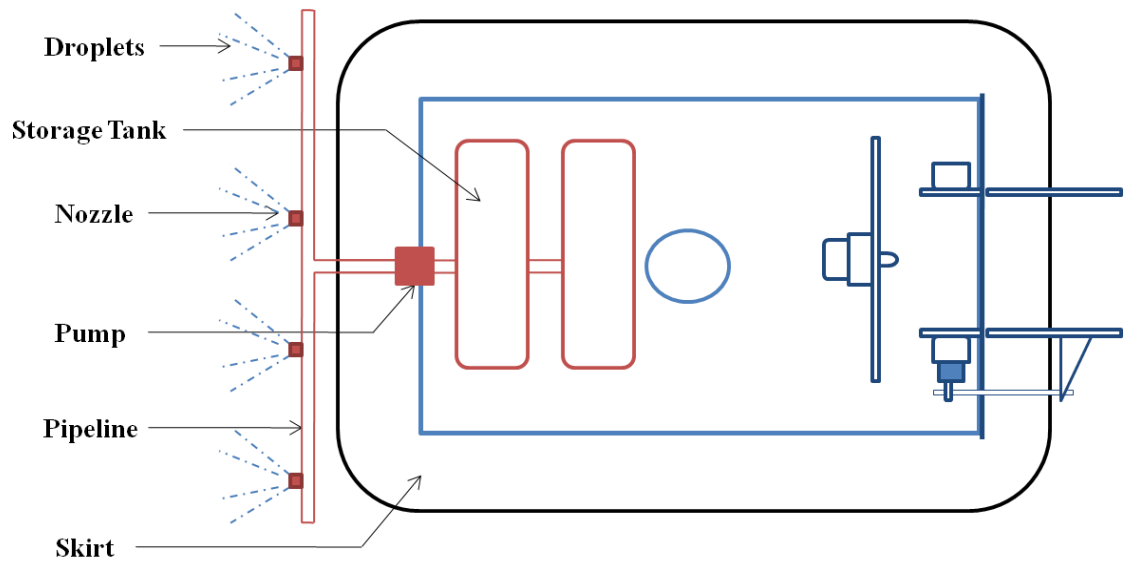

Figure 19. Hovercraft with sprayer

The spraying system is mounted at the hull surface of hovercraft and it is tested on remote water body as shown in Figure 20. For the initial level of testing, water is used as the fluid in the sprayer system. Once the pump is actuated, the fluid from the tank is started to flow into the pipelines and through four nozzles which are positioned in the spacing of $0.165 \mathrm{~m}$ and of height $0.115 \mathrm{~m}$ from the surface. The atomized droplets through nozzles are sprayed over the surface for a swath width of $0.74 \mathrm{~m}$. The field testing on water surface confirms the developed amphibious vehicle is able to spray liquids effectively.

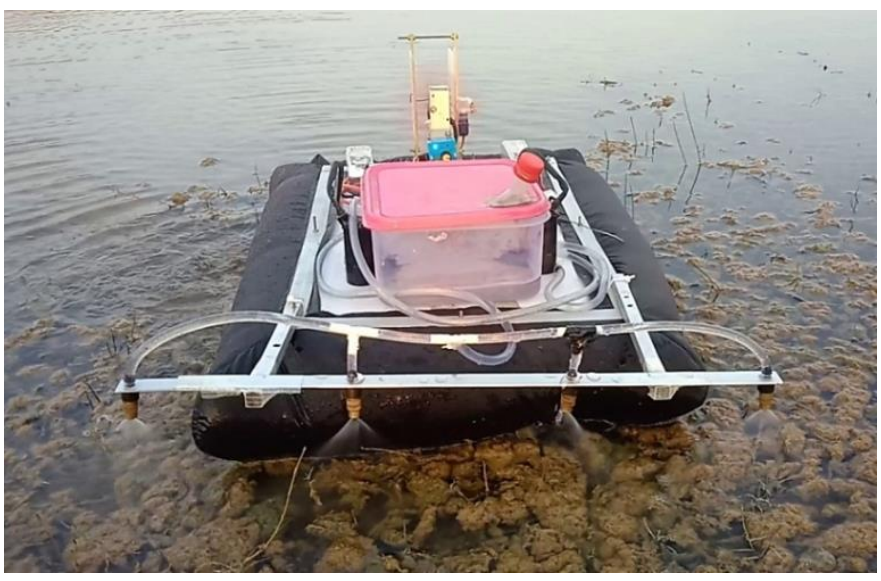

Figure 20. Testing of sprayer over algae

\section{Conclusion}

Unmanned hovercraft of length $0.6 \mathrm{~m}$ with $2.0 \mathrm{~kg}$ all-up weight is developed for pollution control of water bodies. Based upon design calculations, various geometric parameters of hovercraft like Hull depth of $0.06 \mathrm{~m}$, cushion clearance of $0.042 \mathrm{~m}$, hovercraft height of $0.102 \mathrm{~m}$ are determined. The CAD model has undergone CFD analysis and results suggested that there is no blockage of air flow inside the plenum chamber. Modelling and simulations are fused to determine the cognate 
International Journal of Mathematical, Engineering and Management Sciences

Vol. 4, No. 5, 1180-1195, 2019

https://dx.doi.org/10.33889/IJMEMS.2019.4.5-093

range of pressure acting inside the skirt which ranges from $168.97 \mathrm{~N} / \mathrm{m}^{2}-176.01 \mathrm{~N} / \mathrm{m}^{2}$ and it is coherent with experimental results. Preliminary test results show that the design of bag skirt possesses good stability of the vehicle in static and dynamic conditions. The developed test rig is utilized to estimate the input power requirement of $80 \mathrm{~W}$ to lift the entire amphibious vehicle and it is proven. In addition, the forward thrust system is capable of providing the required amount of thrust force of $2.09 \mathrm{~N}$ to achieve gliding at a maximum speed of $2 \mathrm{~m} / \mathrm{sec}$. A sprayer system of $800 \mathrm{~g}$ is incorporated into the vehicle and real time testing is performed at remote water body. Test results indicated that the developed amphibious vehicle with sprayer mechanism is water worthy to clean the water surfaces with good stability.

\section{Conflict of Interest}

The authors affirm that there is no conflict of interest to be declared for this publication.

\section{Acknowledgement}

The Authors would like to thank the funding support from DST - GITA (Ref: 2015RK0201103) under Indo - Korea joint research collaboration. The technical assistance from Centre for Autonomous System Research and Dept. of Aeronautical Engineering, Vel Tech Rangarajan Dr.Sagunthala R\&D Institute of Science and Technology are also greatly acknowledged.

\section{References}

Amyot, J.R. (Ed.). (2013). Hovercraft technology, economics and applications (Vol. 11). Elsevier.

Amiruddin, A.K., Sapuan, S.M., \& Jaafar, A.A. (2011). Development of a hovercraft prototype with an aluminium hull base. International Journal of Physical Sciences, 6(17), 4185-4194.

Anguah, K., \& Szapiro, N. (2009). Design and construction of a passenger hovercraft. E90 final report.

Anter, T.A., Hossamel-din, Y.H., \& Abdrabbo, S.M. (2017, September). An autonomous hovercraft with minimum energy consumption. In 2017 International Conference on Research and Education in Mechatronics (REM) (pp. 1-7). IEEE.

Chung, J., \& Jung, T.C. (2004). Optimization of an air cushion vehicle bag and finger skirt using genetic algorithms. Aerospace Science and Technology, 8(3), 219-229.

Esakki, B., Ganesan, S., Mathiyazhagan, S., Ramasubramanian, K., Gnanasekaran, B., Son, B., Park, S.W., \& Choi, J.S. (2018). Design of amphibious vehicle for unmanned mission in water quality monitoring using internet of things. Sensors, 18(10), 3318.

García, D. (2014). Dynamic, Simulation and Control Design of an Unmanned Hovercraft. I+ D Tecnológico, 10(2), 40-47.

Gera, P., Sarkar, S., Jha, R., Raj, R., Bardhan, R., \& Gupta, S. (2009, January). Design, fabrication and industrial application of a miniature hovercraft. In ASME 2009 International Design Engineering Technical Conferences and Computers and Information in Engineering Conference (pp. 665-674). American Society of Mechanical Engineers.

Hasnan, K., \& Wahab, A.A. (2010, December). Towards the conceptual design and construction of an unmanned small-scale air-land-water vehicle. In 2010 International Conference on Computer Applications and Industrial Electronics (pp. 98-103). IEEE. 
International Journal of Mathematical, Engineering and Management Sciences

Vol. 4, No. 5, 1180-1195, 2019

https://dx.doi.org/10.33889/IJMEMS.2019.4.5-093

Hein, S.M., \& Liaw, H.C. (2013). Design and development of a compact hovercraft vehicle. IEEE/ASME International Conference on Advanced Intelligent Mechatronics, (pp. 1516-1521). Wollongong, Australia.

Hovercraft.org (2013, December 13). hovercraft-environment. Retrieved December 12, 2018, from www.hovercraft.org: http://www.hovercraft.org/hovercraft-environment/

Lamberson, J., \& Nelson, W. (2002). Environmental monitoring and assessment program national coastal assessment field operations: west coast field sampling methods-Intertidal 2002. US Environmental Protection Agency, Newport.

Lynch Jr, W.E. (2009). Controlling filamentous algae in ponds. School of Environment and Natural Resources, Ohio State University, US.

Miková, T.L., Gmiterko, A., \& Lubica, E.P. (2014). Design of mobile robot based on hovercraft. CER Comparative European Research 2014, 101.

Noor, S.M., Syam, K., Jaafar, A.A., Sharif, M.M., Ghazali, M.R., Ibrahim, W.I., \& Atan, M.F. (2016, February). Development of a working hovercraft model. In IOP Conference Series: Materials Science and Engineering (Vol. 114, No. 1, p. 012150). IOP Publishing.

Okafor, B.E. (2013). Development of a hovercraft prototype. International Journal of Engineering and Technology, 3(3), 276-281.

Pavăl, M.S., Popescu, A., Popescu, T., Zahariea, D., \& Husaru, D.E. (2018, November). Numerical study on the movement of air inside the inner cavity of a hovercraft model. In IOP Conference Series: Materials Science and Engineering (Vol. 444, No. 8, p. 082005). IOP Publishing.

Pope, G.G. (1976). An evaluation of a light hovercraft as a spraying platform and survey craft in the UK and Botswana. PANS, 22(1), 132-136.

Saad, K.A.M., Murugan, K., \& Ramli, M.A.H. (2018). The development of hovercraft design with a horizontal propulsion system. In Engineering Applications for New Materials and Technologies (pp. 91103). Springer, Cham.

Schaltz, E., \& Soylu, S. (2011). Electrical vehicle design and modeling. Electric Vehicles-Modelling and Simulations, 1, 1-24.

Schleigh, J. (2006). Construction of a hovercraft model and control of its motion (Doctoral dissertation). University of Maryland, USA.

Yan, R.J., Pang, S., Sun, H.B., \& Pang, Y.J. (2010). Development and missions of unmanned surface vehicle. Journal of Marine Science and Application, 9(4), 451-457.

Yun, L., \& Bliault, A. (2000). Theory and design of air cushion craft. Elsevier. 